International Journal of Advanced Chemistry, 9(2)(2021) 146-149
International Journal of Advanced Chemistry
SPC
Website: $w w w$. sciencepubco.com/index.php/IJET
Research paper

\title{
Characterization of biomass residue (yam peels) for bioethanol production
}

\author{
Abdulrahman Bashir*, Nasirudeen Mohammed Baba, and Timothy M. Akpomie \\ Department of Chemistry, Federal University of Lafia, P.M.B 146, Nasarawa, Nigeria \\ *Corresponding author E-mail: bashir.abdurrahmanatk@gmail.com
}

\begin{abstract}
The potential of yam peels for bioethanol production was investigated through an understanding of their compositional profile. The yam peels dried powder was subjected to X-ray diffraction analysis, and it was examined for proximate and biochemical composition. The result of the biochemical analysis of the yam peels showed the following: holocellulose (57.93\%) [cellulose (29.02\%) + hemicellulose (28.91\%)] and lignin $(27.43 \%)$, while the proximate analysis showed the following: moisture $(11.11 \%)$, ash $(5.93 \%)$, and volatile matter $(68.4 \%)$. Consequently, the X-ray diffraction pattern shows the presence of amorphous and crystalline region in the sample. The result showed that the yam peels possesses low lignin and high holocellulose content. This study indicate that the yam peels are potential candidates for bioethanol production.
\end{abstract}

Keywords: Holocellulose; Lignin; Proximate Analysis; Bioethanol.

\section{Introduction}

In a world that is threatened by climate change, instability in major oil-producing countries and rural economic decline, efforts to replace petroleum with alternative energy is gaining attention. This has led to an increased interest in producing biofuels by utilizing agricultural crops, wastes and residues. Carbon dioxide are taken from atmosphere by biofuel crops while they grow, hence offsetting the greenhouse gases released when the fuel is subsequently burned. Air pollution can be minimized by replacing fossil fuel with biofuel. Rural economies can be improved through creation of jobs and raising farm incomes by production of biofuel. Bioethanol as a locally produced fuel has the potential to improve trade balances in oil-importing nations, diversify energy portfolios, and lower dependence on foreign oil (Daniella, 2008).

In recent years, renewable energy supplies have gained a lot of interest globally for a number of reasons. The level of greenhouse gases and other pollutants in the atmosphere with all their attendant problems which include acid rains, global warming and various health disorders have increased due to excessive usage of fossil fuels, which provide about $90 \%$ of world energy supply (Hinrichs and Kleinbach, 2002). Renewable energy supplies as replacement for fossil fuels is now accepted as a means to reduce the negative impacts of dependence on fossil fuels. Economic growth through development of manufacturing or agricultural sector can be stimulated by promoting the use of renewable energy.

Rabah et al. (2011) reported that bioethanol has the potential to diversify energy portfolios, lower dependence on foreign oil, and improve trade balances in oil-importing nations. Hence, the aim of this study is to investigate the potential of yam peels for bioethanol production through an understanding of their compositional profile.

\section{Materials and methods}

\subsection{Biomass sample pretreatment}

The biomass sampling was carried out as described by Awoyale et al. (2009). In the present study, yam peels as residue from agricultural crops were used as biomass sources. The yam peels samples were sourced locally from Kaduna North L.G.A, Kaduna State, Nigeria. In conversion of lignocellulosic biomass such as sugarcane bagasse into bioethanol; four major unit operations were employed. These include: pre-treatment, hydrolysis, fermentation and product recovery/distillation. Pre-treatment was the first stage in the production of the bioethanol. The yam peels were sun-dried for three days before milling and sieving to standardize the particle size (Plate 1). The sieved yam peels sample was then stored in plastic jars at ambient temperature. 


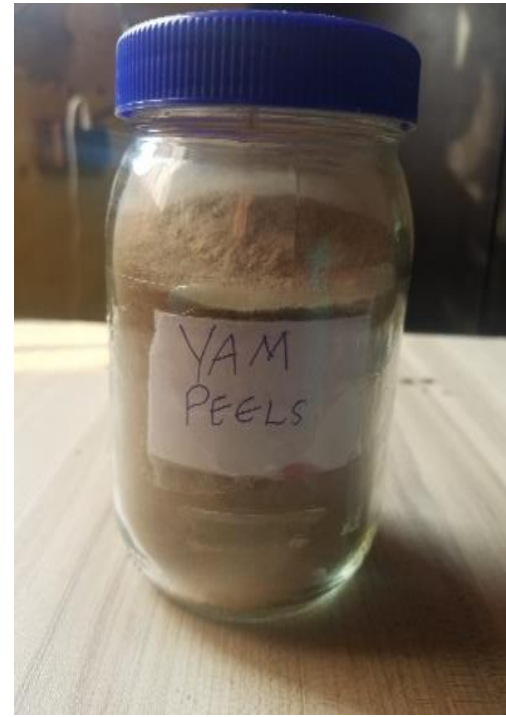

Plate 1: Biomass Sample.

\subsection{Compositional analysis}

Aside from the main components of biomasses namely holocellulose (cellulose and hemicellulose) and lignin content, other parameters measured in proximate analysis includes; the moisture content, ash content, and volatile matter. All reported proximate analysis data were done in triplicate measurements.

\subsubsection{Proximate values}

The proximate values were determine using standard methods of American Society for Testing and Materials (ASTM).

\subsubsection{Determination of lignin and holocellulose (cellulose and hemicellulose)}

Lignin was determined according to the method described by Kim et al., (2012) and Hwangbo et al., (2009). Holocellulose was estimated according to the method described by (Rabemanolontsoa \& Saka, 2012), while the cellulose content in holocellulose was determined according to the method: (Korean Standards Association) KSM 7044, "Testing method for alpha, beta and gamma cellulose in pulp" (Kim et al., 2012). Hemicellulose weight was calculated by subtracting the weight of holocellulose from the weight of cellulose.

\subsection{X-ray diffraction analysis}

X-Ray Diffraction (XRD) was carried out to determine the state of the cellulose in the yam peels. Cellulose contains crystalline and amorphous regions, and a measure of the state of the cellulose is one of the most important measurable properties of cellulose that influences its hydrolysis (Hall et al., 2010). The X-Ray Diffraction (XRD) analysis was performed using Empyrean X-ray Diffractometer.

\section{Results and discussions}

\subsection{Compositional analysis}

\subsubsection{Proximate values of the yam peels}

Using standard analytical procedures, the composition of the yam peels were determined. Table 1 shows the proximate parameters of the yam peels with those reported in literature.

Ash is the total content of dusts and inorganic substances in biomasses and it is estimated to be around $10 \%$ in lignocellulose biomass (Yanqing et al., 2014). From the Table 1, the result indicate that the yam peels has low ash content 5.93\%. In biomass pretreatment prior to fermentation, high ash content is a drawback as the ash particles absorb more steam, water, dilute acid solution or solvent than the relatively larger lignocellulosic fibers. This therefore reduces the efficiency of the pretreatment process and will also lead to increase in production cost (Bruun et al., 2010). With exception of rice husk, the result of this study conforms to results of cassava peels from previous works by other researchers. The low ash content of the biomass waste further goes to confirm that the yam peels is good feedstock for bioethanol production.

The proximate analyses of volatile matter was found to be $68.40 \%$. The high amount of volatile matter in the yam peels is an indication that they can be harnessed to produce energy by combustion (Ferreira et al., 2015). The volatile matter of the yam peels presented in this study conforms to the report of Ferreira et al. (2015).

High moisture content absorbs heat that would otherwise be available (Charlton et al., 2009). The moisture content of the yam peels in this study is considerable lower than that reported for cassava peels but slightly above that reported for rice husk. Charlton et al. (2009) had reported that, low moisture content will help in reducing the cost of bioethanol production process. 


\subsubsection{Lignin and holocellulose (cellulose and hemicellulose) values of the yam peels}

The major composition of lignocellulose feedstock includes; holocellulose (cellulose and hemicellulose) and small amount of lignin (Oberoi et al., 2010). Holocellulose is a white solid that is lignin-free but comprised of both cellulose and hemicellulose. The plant cell wall structure is composed mainly of cellulose which gives it mechanical vigour and chemical stability. Cellulose is the form in which the

Table 1: Comparison between the Proximate Values of the Yam Peels and Rice Husk and Cassava Peels

\begin{tabular}{llll}
\hline Parameters & Result of Present Study $(\%)$ & Reported Values for Rice Husk $(\%)$ & Reported Values for Cassava Peels $(\%)$ \\
\hline Moisture & 11.11 & $8.00^{\mathrm{a}}, 8.19^{\mathrm{b}}$ & $15.13^{\mathrm{b}}, 14.12^{\mathrm{c}}$ \\
Volatile matter & 68.40 & $71.24^{\mathrm{a}}$ & - \\
Ash & 5.93 & $12.50^{\mathrm{a}}, 14.89^{\mathrm{d}}$ & $4.50^{\mathrm{f}}, 3.23^{\mathrm{e}}$ \\
\hline
\end{tabular}

a. (Ferreira et al., 2015), b. (Awoyale et al., 2009), c. (Ebabhi et al., 2018), d. (Quintero et al., 2013), e. (Sivamani \& Baskar, 2015), and f. (Aripin et al., 2013).

Solar energy absorbed by the process of photosynthesis is stored in the plant. Hemicellulose is a copolymer of various C5 and C6 sugars existing in the plant cell wall. The main feature that differentiates hemicellulose from cellulose is that hemicellulose has branches with short lateral chains consist of different type of sugars. In contrary to cellulose, the polymer present in hemicellulose is hydrolysable (Fatin Afifah and Khairiah, 2014). Lignin is a polymeric compound comprising of the aromatics and is formed through a biosynthetic process. It constitutes the protective covering for the cell wall of plants. Aside these three chemical compounds contained in the lignocellulose biomass, other compounds contained therein includes: water, small amount of proteins, ash, organic acids and minerals. The holocellulose (cellulose and hemicellulose) provide the sugar needed for the bioconversion to bioethanol (Malherbe \& Thomas, 2002). Lignin is a phenolic polymer, which is a major feedstock for industrial processes for example, adhesive resin and lignin gels (Pizzi \& Joan, 2007). The main function of lignin in the plant cell wall is for structural support, impenetrability and resistance against microbial attack and oxidative stress. It is also an amorphous heteropolymer which is insoluble in water. These factors make the degradation of lignin a very arduous task (Hendriks \& Zeeman, 2009). Pretreatment of the biomass is therefore of utmost importance to break the lignin barrier in the plant cell wall and make the holocellulose (cellulose and hemicellulose) available during fermentation.

Holocellulose, cellulose, hemicellulose and lignin are $57.93 \%, 29.02 \%, 28.91 \%$ and $27.43 \%$ respectively as shown in Table 2 . The result shows that the yam peels has low lignin content and is rich in holocellulose (cellulose and hemicellulose), which forms the basis for its conversion into bioethanol. The fact that it has high holocellulose content, means that it is a good and ready source of raw material for bioethanol production (Awoyale et al., 2009). Compared to reported literature, the value of the sugar content obtained in this study shows a significant variation from reported values, the sugar content is higher than that reported for rice husk but less than that for cassava peels, also the biomass waste in this study shows yam peels to have higher lignin value compared to that reported for rice husk and cassava peels from previous works as show in the Table 2 .

Suk-Jun et al. (2015) who worked on the comparison of lignin, cellulose, and hemicellulose contents for biofuels utilization among four types of lignocellulosic crops reported that, lignin content ranged from 13.90 to $26.20 \%$, cellulose content ranged from 29.50 to $37.80 \%$, hemicellulose content ranged from 21.30 to $29.90 \%$, and holocellulose content ranged from 53.80 to $64.20 \%$. These results shown in the Table 2 conformed to the ranges reported by Suk-Jun et al. (2015).

\subsection{X-ray diffraction of the yam peels}

Figures 1 shows the X-ray diffraction patterns of the yam peels. Given that amorphous regions are not identified by XRD, the presence of amorphous is only inferred in samples displaying significant rise in their XRD baseline pattern as the $2 \theta$ value increases. According to Gaydon (2011), a rise in the baseline of XRD pattern with increase in the $2 \theta$ value is indicative of the presence of amorphous region. In this case, the wide peak observed which centered at $2 \theta=20^{\circ}$ suggested the amorphous structure of the yam peels. This conforms to the results obtained from previous research (Awoyale et al., 2009). Intense sharp peak was shown by the yam peels, characteristic of cellulose at $2 \theta=28^{\circ}$ and between $38^{\circ}-45^{\circ}$, these peaks are commonly attributed to the presence of crystalline cellulose (Adeolu \& David, 2021).

Table 2: Comparison between the Composition of Sugar in the Yam Peels with Reported Literatures

\begin{tabular}{llll}
\hline Parameters & Result of Present Study (\%) & Reported Values for Rice Husk (\%) & Reported Values for Cassava Peels (\%) \\
\hline Holocellulose & 57.93 & $53.74^{\mathrm{a}}, 52.86^{\mathrm{b}}$ & $74.90^{\mathrm{c}}, 37.40^{\mathrm{d}}$ \\
Hemicellulose & 28.91 & $27.29^{\mathrm{a}}, 32.00^{\mathrm{b}}$ & $37.00^{\mathrm{c}}, 11.60^{\mathrm{d}}$ \\
Cellulose & 29.02 & $26.45^{\mathrm{a}}, 20.86^{\mathrm{b}}$ & $37.90^{\mathrm{c}}, 25.80^{\mathrm{d}}$ \\
Lignin & 27.43 & $18.60^{\mathrm{a}}, 30.01^{\mathrm{b}}$ & $7.50^{\mathrm{c}}, 4.29^{\mathrm{d}}$ \\
\hline
\end{tabular}

a. (Quintero et al., 2013), b. (Woottichai et al.,2015), c. (Aripin et al., 2013) and d. (Awoyale et al., 2009).

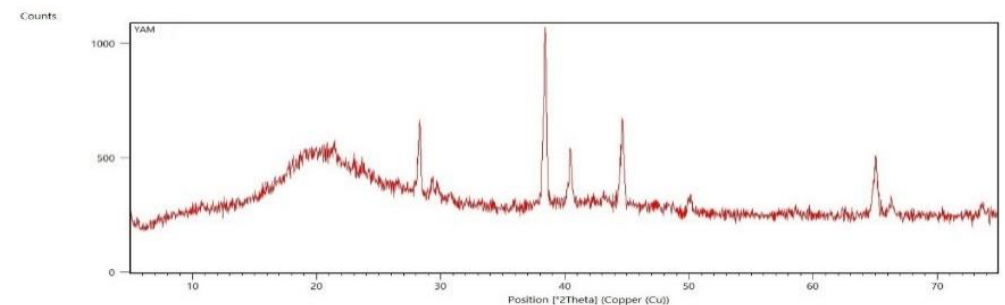

Fig. 1: X-Ray Diffraction of the Yam Peels.

\section{Conclusion}

Yam peels was characterized in this study for bioethanol production. The high holocellulose content (cellulose $29.02 \%$ and hemicellulose $28.91 \%$ ) of the biomass waste makes it a potential candidate for bioethanol production. These results therefore point the fact that the yam peels presented in this study is a good feedstock for bioethanol opportunities. However, as in any study, ours may have limitation, including 
variations in the methods and materials used, the collection sites selected, and the prevailing climatic conditions during the study. Therefore, additional investigations on other lignocellulosic crops for bioethanol production are warranted.

\section{References}

[1] Adeolu, A. A., \& David, L. (2021). Experimental Determination of the Effects of Pretreaatment on Selected Nigerian Lignocellulosic Biomass in Bioethanol Production. Natyre Research, 11(557), 1-16. https://doi.org/10.1038/s41598-020-78105-8.

[2] Awoyale, A. A., Lokhat, D., \& Eloka-Eboka, A. C. (2009). Experimental characterization of selected Nigerian lignocellulosic biomasses in Bioethanol production. International Journal of Ambient Energy, 2162-8246. https://doi.org/10.1080/01430750.2019.1594375.

[3] Bruun, S., Jensen, J. W., Magid, J., Lindedam, J., \& Engelse, S. B. (2010). Prediction of the degradability and ash content of wheat straw from different cultivars using near infrared spectroscopy. Ind. Crops Prod, 321-326. https://doi.org/10.1016/j.indcrop.2009.11.011.

[4] Charlton, A., Elias, R., Fish, S., Fowler, P., \& Gallagher, J. (2009). he biorefining opportunities in Wales: understanding the scope for building a sustainable, biorenewable economy using plant biomass. Chem. Eng. Res. Des., 1147-1161. https://doi.org/10.1016/i.cherd.2009.06.013.

[5] Daniella, M. (2008). Ethanol's potential: Looking Beyond Corn. Intern. J. Microbiol, 453-460.

[6] Fatin Afifah, B. K., \& Khairiah, H. B. (2014). Effect of cooking temperature on the crystallinity of acid hydrolysed-oil palm cellulose. AIP Conference Proceedings, 1641, pp. 456 - 462. https://doi.org/10.1063/1.4895240.

[7] Ferreira, M. M., Schmidt, F. L., \& Ferreira, M. M. (2015). Analysis of the lignocellulosic components of biomass residues for biorefinery opportunities. Elsevier, 14(4), 696-703. https://doi.org/10.1016/j.talanta.2015.06.045.

[8] Gaydon, J. W. (2011). The Application of a Near-Infrared Sensor to Sorting of Minerals. Camborne School of Mines, University of Exeter, Penryn Campius, United Kingdom: Ph.D. thesis.

[9] Hall, M., Bansal, P., Lee, J., Realff, M., \& Bommarius, A. (2010). Cellulose crystallinity - a key predictor of the enzymatic hydrolysis rate. FEBS J, 277, 1571-1582. https://doi.org/10.1111/j.1742-4658.2010.07585.x.

[10] Hinrichs, R. A., \& Kleinbach, M. (2002). Energy: Its use and the environment (5th ed.). Belmont: Cengage Learning.

[11] Hinrichs, R. A., \& Kleinbach, M. (2002). Energy: Its use and the environment (5th ed.). Belmont: Cengage Learning.

[12] Hwangbo, J. K., Seo, J. K., \& Kwak, Y. S. (2009). The pretreatment of lignocellulosic biomass for bioethanol production. RIST, 23(2), 126-131.

[13] Kim, S. J., Kim, M. Y., Jeong, S. J., Jang, M. S., \& Chung, I. M. (2012). Analysis of the biomass content of various Miscanthus genotypes for biofuel production in Korea. Ind.Crops Prod., 46-49. https://doi.org/10.1016/j.indcrop.2012.01.003.

[14] Malherbe, S., \& Thomas, E. C. (2002). Lignocellulose biodegradation: fundamentals and applications. Reviews in Environmental Science and Biotechnology, 105-114. https://doi.org/10.1023/A:1020858910646.

[15] Oberoi, Harinder, S., Ramabhau, Praveen, V. V., Khushal, B., Vinod, B. K., \& Tumadu, P. (2010). Enhanced ethanol production via fermentation of rice straw with hydrolysate-adapted Candida tropicalis ATCC 13803." Process Biochemistry. 45(8), 1299-1306. https://doi.org/10.1016/j.procbio.2010.04.017.

[16] Pizzi, A., \& Joan, S. (2007). Lignin-based wood panel adhesives without formaldehyde. Holz als Roh-und Werkstoff, 1(65), 65. https://doi.org/10.1007/s00107-006-0130-z.

[17] Rabah, A. B., Oyeleke, S. B., Manga, B. S., \& Hassan, L. G. (2011, December). Dilute acid pretreatment of millet and guineacorn husks for bioethanol production. International Research Journal of Microbiology (IRJM), 2(11), 460-465. Retrieved from http://www.interesjournals.org/IRJM

[18] Rabemanolontsoa, H., \& Saka, S. (2012). Holocellulose determination in biomass, in: T. Yao (Ed.), Zero-carbon Energy Kyoto 2011. Springer, Japan, 135-140. https://doi.org/10.1007/978-4-431-54067-0_14.

[19] Suk-Jun, J., Seung-Hyun, K., \& Ill-Min, C. (2015). Comparison of lignin, cellulose, and hemicellulose contents fornbiofuels utilization among 4 types of lignocellulosic crops. Biomass and Bioenergy, 322-327. https://doi.org/10.1016/j.biombioe.2015.10.007.

[20] Yanqing, H., Zhenhong, F., Jian, Z., Xinliang, L., \& Jie, B. (2014). De-ashing treatment of corn stover improves the efficiencies of enzymatic hydrolysis and consequent ethanol fermentation. Bioresource technology, 169, 552-558. https://doi.org/10.1016/j.biortech.2014.06.088. 